\title{
Analgesic and Anti-Inflammatory Activities of Leaf Extract of Mallotus repandus (Willd.) Muell. Arg.
}

\author{
Md. Mahadi Hasan, ${ }^{1}$ Nizam Uddin, ${ }^{1}$ Md. Rakib Hasan, ${ }^{2}$ A. F. M. Mahmudul Islam, ${ }^{2}$ \\ Md. Monir Hossain, ${ }^{1}$ Akib Bin Rahman, ${ }^{2}$ Md. Sazzad Hossain, ${ }^{2}$ \\ Ishtiaque Ahmed Chowdhury, ${ }^{2}$ and Md. Sohel Rana ${ }^{1}$ \\ ${ }^{1}$ Laboratory of Natural Products Research, Department of Pharmacy, Jahangirnagar University, Savar, Dhaka 1342, Bangladesh \\ ${ }^{2}$ Department of Pharmacy, Jahangirnagar University, Savar, Dhaka 1342, Bangladesh
}

Correspondence should be addressed to Md. Mahadi Hasan; mahadipharm@gmail.com

Received 29 August 2014; Revised 9 November 2014; Accepted 11 November 2014; Published 31 December 2014

Academic Editor: Daniela Parolaro

Copyright (C) $2014 \mathrm{Md}$. Mahadi Hasan et al. This is an open access article distributed under the Creative Commons Attribution License, which permits unrestricted use, distribution, and reproduction in any medium, provided the original work is properly cited.

In folk medicine Mallotus repandus (Willd.) Muell. Arg. is used to treat muscle pain, itching, fever, rheumatic arthritis, snake bite, hepatitis, and liver cirrhosis. This study aimed to evaluate the antinociceptive as well as the anti-inflammatory activities of the methanol extract of leaf. The leaves were extracted with methanol following hot extraction and tested for the presence of phytochemical constituents. Analgesic and anti-inflammatory activities were evaluated using acetic acid induced writhing test, xylene induced ear edema, cotton pellet induced granuloma, and tail immersion methods at doses of 500, 1000, and 2000 mg/kg body weight. The presence of flavonoids, saponins, and tannins was identified in the extract. The extract exhibited considerable antinociceptive and anti-inflammatory activities against four classical models of pain. In acetic acid induced writhing, xylene induced ear edema, and cotton pellet granuloma models, the extract revealed dose dependent activity. Additionally, it increased latency time in tail immersion model. It can be concluded that M. repandus possesses significant antinociceptive potential. These findings suggest that this plant can be used as a potential source of new antinociceptive and anti-inflammatory candidates. The activity of methanol extract is most likely mediated through central and peripheral inhibitory mechanisms. This study justified the traditional use of leaf part of this plant.

\section{Introduction}

Mallotus repandus (Willd.) Muell. Arg. locally known as Gunti, Jhante, or Bon Natai in Bangladesh belongs to family Euphorbiaceae, an herbaceous plant which looks like a shrub or small tree that is widely distributed and naturally grown at Sundarban, Savar, and Sylhet regions in Bangladesh. Mallotus is one of the richest genera of the Euphorbiaceae family. The genus Mallotus consists of around 150 species widely distributed in tropical and subtropical regions in Asia (Cambodia, China, India, Laos, Malaysia, Sri Lanka, Thailand, and Vietnam). A small number of species are found in the North and East of Australia and the Pacific-Ocean Archipelago (the East of Fiji). Aerials parts, bark, heartwood, leaves, roots, seeds, stem bark, and whole plants are the parts of the Mallotus species to undertake any research work.
A quantity of Mallotus species is acknowledged to have diverse natural compounds, principally terpenoids, polyphenols, and benzopyrans. Antioxidant, antiviral, antimicrobial, cytotoxicity and anti-inflammatory properties are different sorts of therapeutic properties shown by the isolated compounds from the extracts of Mallotus genus. Some of these properties are recognized in the presence of definite classes of natural compounds, for example, polyphenols responsible for the antiradical activity of Mallotus metcalfianus extracts [1] or benzopyrans responsible for the cytotoxicity of Mallotus apelta extracts $[2,3]$.

Mallotus repandus has been locally used in an herbal formula for the relief of muscle pain in Thailand [4]. In Taiwan the leaves of Mallotus repandus have been used as anti-inflammatory drugs [5]. In addition, it has been used as an insecticide to stop itching and as a therapy for 
fever, rheumatic arthritis, snake bite, hepatitis, and liver cirrhosis $[6,7]$. Therefore, this study was undertaken to justify analgesic and anti-inflammatory potentials of the leaf part of $M$. repandus (MLM) using in vivo assay models.

\section{Materials and Methods}

2.1. Drugs, Chemicals, and Apparatus. Methanol was bought from SIGMA (Sigma-Aldrich, St. Louis, USA). Pentazocine and Diclofenac Na were obtained from Beximco Pharmaceuticals Ltd., Bangladesh. Heparin inj. was purchased from Rotexmedica, Germany. All the chemicals and reagents were of analytical grade.

2.2. Collection of Plant Material. Leaves of Mallotus repandus were collected from local area of Savar and authenticated by an expert taxonomist. A voucher specimen (number 39503) was deposited in the herbarium for future reference.

2.3. Preparation of Methanolic Extract. The collected plant parts of leaf were cleaned and washed well with water. The cleansed leaves were then partially dried by fan aeration and then fully dried in the oven at below $40^{\circ} \mathrm{C}$ for 4 days. The fully dried parts were then ground to a powdered form and stored in suitable condition for few days. The powdered plant materials of leaf $(480 \mathrm{gm})$ were used for extraction by Soxhlet apparatus at elevated temperature $\left(65^{\circ} \mathrm{C}\right)$ using petroleum ether and ethyl acetate $(500 \mathrm{~mL})$, respectively. After complete exhaustion the powder was then treated with $500 \mathrm{~mL}$ of methanol. Resulting methanol extract was filtered through fresh cotton bed. The filtrate obtained was dried at temperature of $40 \pm 2^{\circ} \mathrm{C}$ to have gummy concentrate of the crude extract. It was kept in suitable container with proper labeling and stored in cold and dry place. The yield value for methanol extract was $12.79 \%$.

2.4. Animals and Experimental Setup. Sprague-Dawley female rats of $120-140 \mathrm{~g}$ and Swiss albino female mice of 25-30 g were collected from Pharmacology Laboratory, Department of Pharmacy, Jahangirnagar University, and were acclimatized to normal laboratory conditions for one week prior to study and were assessed to pellet diet and water ad libitum. Temperature of facility was $25 \pm 3{ }^{\circ} \mathrm{C}$ and light/darkness alternated 12 hours apart. The animals were divided into five groups of five animals each. The study was conducted following the approval by the Institutional Animal Ethical Committee of Jahangirnagar University, Savar, Dhaka, Bangladesh.

2.5. Phytochemical Screening. The methanol extract of Mallotus repandus leaf underwent phytochemical screening to detect the presence of potential phytochemical constituents like alkaloids, carbohydrates, flavonoids, saponins, tannins, glycosides, steroids, and terpenoids [8].

2.6. Acute Toxicity Study. According to the OECD guideline, mice were divided into five groups of ten animals each. Different doses $(250,500,1000,2000$, and $4000 \mathrm{mg} / \mathrm{kg})$ of methanol extract were administered by stomach tube. Then the animals were observed for general signs of toxicity.
2.7. Tail Immersion Test. The tail immersion method was also used to evaluate the central mechanism of analgesic activity. Here the painful reactions in animals were produced by thermal stimulus, that is, by dipping the tip of the tail in hot water [9]. Swiss albino mice were grouped and treated with 500,1000 , and $2000 \mathrm{mg} / \mathrm{kg}$ body weight, respectively. Here, pentazocine $(10 \mathrm{mg} / \mathrm{kg})$ is used as a reference drug as well. Control group received only vehicle. The animals were fasted for 16 hours with water ad libitum. After administration of standard and test drugs, the basal reaction time was measured by immersing the tail tips of the mice (last $1-2 \mathrm{~cm}$ ) in hot water heated at temperature $55 \pm 1^{\circ} \mathrm{C}$. The actual flick response of mice, that is, time taken in seconds to withdraw it from hot water source, was calculated and results were compared with control group. Mice with baseline latencies of more than $10 \mathrm{~s}$ were eliminated from the study, a latency period of $15 \mathrm{~s}$ was set as the cutoff point, and the measurement was then stopped to avoid injury to mice. The latent period of the tailflick response was determined at $0,1,2,3$, and $4 \mathrm{~h}$ after the administration of drugs.

2.8. Acetic Acid Induced Writhing. The method according to Koster et al. [10] was employed for this test. Five groups of mice (5 mice in each group) were pretreated with control, Diclofenac Na $(100 \mathrm{mg} / \mathrm{kg})$ and the extract $(500,1000$ and $2000 \mathrm{mg} / \mathrm{kg}$ ). Forty-five minutes later each mouse was injected i.p. with $0.7 \%$ acetic acid at a dose of $10 \mathrm{~mL} / \mathrm{kg}$ body weight. The number of writhing responses was recorded for each animal during a subsequent $5 \mathrm{~min}$ period after $15 \mathrm{~min}$ i.p. administration of acetic acid and the mean abdominal writhing for each group was obtained.

The percentage inhibition of writhing was calculated using the following formula:

$\%$ Inhibition

$$
=\left(1-\frac{\text { No. of Writhing (Drug/Standard) }}{\text { No. of Writhing (Control) }}\right) \times 100 \text {. }
$$

2.9. Xylene Induced Ear Edema in Mice. The xylene induced ear edema test was performed as described by Dai et al. [11]. The tested samples including Diclofenac $\mathrm{Na}(100 \mathrm{mg} / \mathrm{kg})$ as a positive control were given orally to the mice and plant extract was given as described before. One hour later, each animal received $20 \mu \mathrm{L}$ of xylene on the anterior and posterior surfaces of the right ear lobe. The left ear was considered as control. Mice were sacrificed one hour after xylene application and circular sections were taken, using a cork borer with a diameter of $3 \mathrm{~mm}$, and weighed. The weight of edema was considered as the difference between weight of ear treated with xylene (right ear) and the weight of ear without xylene treatment (left ear).

The percentage inhibition of ear edema was calculated by the following formula:

$\%$ Inhibition

$$
=\left(1-\frac{\text { Weight of Edema (Drug/Standard) }}{\text { Weight of Edema (Control) }}\right) \times 100 \text {. }
$$


TABle 1: Phytochemical constituents identified in methanol extract of M. repandus leaf (MLM).

\begin{tabular}{|c|c|c|c|}
\hline Phytochemical & Name of the tests & Observed changes & Result \\
\hline \multirow{5}{*}{ Alkaloids } & Mayer's test & Creamy white precipitate & - \\
\hline & Hager's test & Yellow crystalline precipitate & + \\
\hline & Wagner's test & Brown or deep brown precipitate & - \\
\hline & Dragendorff's test & Orange or orange-red precipitate & - \\
\hline & Tannic acid test & Buff color precipitate & - \\
\hline \multirow{5}{*}{ Carbohydrates } & Molisch's test & $\begin{array}{l}\text { A red or reddish violet ring is formed at the } \\
\text { junction of two layers and on shaking a dark } \\
\text { purple solution is formed }\end{array}$ & + \\
\hline & $\begin{array}{l}\text { Barfoed's test (general test } \\
\text { for monosaccharides) }\end{array}$ & Red precipitate & - \\
\hline & Fehling's test & A red or brick-red precipitate & - \\
\hline & Benedict's test & & + \\
\hline & $\begin{array}{l}\text { Test for combined reducing } \\
\text { sugar }\end{array}$ & A brick-red precipitate & - \\
\hline \multirow{3}{*}{ Glycosides } & General test & Yellow color & - \\
\hline & Bromine water test & yellow precipitate & + \\
\hline & Test for glucoside & $\begin{array}{l}\text { Production of brick-red precipitation (carried out } \\
\text { with the hydrolyzed extract) }\end{array}$ & - \\
\hline \multirow{3}{*}{ Flavonoids } & Alkaline reagent test & Red color & $+1-$ \\
\hline & $\begin{array}{l}\text { Shinoda test (magnesium } \\
\text { hydrochloride reduction } \\
\text { test) }\end{array}$ & Green to blue color & + \\
\hline & $\begin{array}{l}\text { Zinc hydrochloride } \\
\text { reduction test }\end{array}$ & Red color after few minutes & - \\
\hline Saponins & Frothing test & Formation of stable foam & + \\
\hline Steroids & Libermann-Burchard's test & Greenish color & - \\
\hline \multirow{3}{*}{ Tannins } & Lead acetate test & A yellow or red precipitate & + \\
\hline & Ferric chloride test & Blue green color & - \\
\hline & Alkaline reagent test & Yellow to red precipitate & + \\
\hline Terpenoids & Salkowski test & Yellow color appears at the lower layer & - \\
\hline
\end{tabular}

$(+)$ = presence; $(-)$ = absence; $(+/-)=$ presence or absence not ascertained.

2.10. Cotton Pellet Induced Granuloma Formation in Rat. The cotton pellet induced granuloma method was performed as described by Swingle and Shideman [12]. Sterilized cotton pellets of $40 \pm 1 \mathrm{mg}$ weight each were impregnated subcutaneously, one on each side of the abdomen of the animal, under ketamine anesthesia and sterile technique. Test drugs were administered orally to test animals, as described before, in a once-daily dosage regimen for 7 days; the control group received vehicle only. Diclofenac $(100 \mathrm{mg} / \mathrm{kg})$ was used as a reference drug. The rats were sacrificed on the 8th day and the cotton was removed and dried at $60^{\circ} \mathrm{C}$ for $24 \mathrm{hrs}$, and dry cotton weight was recorded. The weight difference of dry cotton and the cotton before implantation is considered as weight of granuloma formed.

The percentage inhibition of granuloma formation was calculated by the following formula:

$\%$ Inhibition

$$
=\left(1-\frac{\text { Weight of Granuloma (Drug/Standard) }}{\text { Weight of Granuloma (Control) }}\right) \times 100 \text {. }
$$

2.11. Statistical Analysis. The results were expressed as the mean \pm SEM (standard error of mean). The results were statistically analyzed using repeated measures analysis of variance (RM-ANOVA) and one way ANOVA followed by Dunnett's multiple comparison tests. $P<0.05$ was considered as statistically significant. Statistical programs used were GRAPHPAD PRISM (version 6.00; GraphPad Software Inc., San Diego, CA, USA) and SIGMAPLOT (version 12.0, Systat Software Inc., San Jose, California, USA).

\section{Results}

3.1. Phytochemical Screening. Methanol extract of M. repandus leaf has been shown to possess different types of phytoconstituents including flavonoids, tannins, and saponins (Table 1).

3.2. Acute Toxicity Study. The extract administered up to high dose $(4000 \mathrm{mg} / \mathrm{kg})$ produced no mortality. The animals did not manifest any sign of restlessness, respiratory distress, general irritation, coma, or convulsion. Hence this extract is considered safe for mice. 
TABLE 2: Effects of various extracts of $M$. repandus on the latency time in tail immersion test.

\begin{tabular}{lcccccc}
\hline \multirow{2}{*}{ Group } & Doses $(\mathrm{mg} / \mathrm{kg})$ & \multicolumn{4}{c}{ Latency time $(\mathrm{s})$} \\
& & $0 \mathrm{~h}$ & $1 \mathrm{~h}$ & $2 \mathrm{~h}$ & $3 \mathrm{~h}$ & $4 \mathrm{~h}$ \\
\hline Control & $1 \%$ Tween 80 in water $(10 \mathrm{~mL} / \mathrm{kg})$ & $4.462 \pm 0.196$ & $4.278 \pm 0.370$ & $4.404 \pm 0.243$ & $3.984 \pm 0.334$ & $3.936 \pm 0.314$ \\
Pentazocine & 10 & $4.18 \pm 0.256$ & $8.4 \pm 0.51^{*}$ & $8.294 \pm 0.250^{*}$ & $8.028 \pm 0.96^{*}$ & $6.834 \pm 0.282^{*}$ \\
& 500 & $4.720 \pm 0.343$ & $5.540 \pm 0.431$ & $4.408 \pm 0.556$ & $5.138 \pm 0.186$ & $5.704 \pm 0.639$ \\
MLM & 1000 & $4.314 \pm 0.136$ & $5.990 \pm 1.297$ & $4.164 \pm 0.468$ & $5.058 \pm 0.403$ & $4.742 \pm 0.511$ \\
& 2000 & $4.778 \pm 0.133$ & $7.720 \pm 1.136$ & $6.250 \pm 1.625^{*}$ & $7.540 \pm 1.282^{*}$ & $6.080 \pm 0.460^{*}$ \\
\hline
\end{tabular}

Values are presented in mean $\pm \operatorname{SEM}(n=5) .{ }^{*} P<0.05$ was considered statistically significant when compared against control. Overall time effect is considered extremely significant with $F(4,80)=5.910$ and $P<0.05$. Repeated measure ANOVA with Dunnet's multiple comparison was performed to analyze this data set.

TABLE 3: Effect of Mallotus repandus leaf methanol extract in acetic acid writhing test.

\begin{tabular}{lccc}
\hline Group & Doses $(\mathrm{mg} / \mathrm{kg})$ & Number of writhing responses & Inhibition $(\%)$ \\
\hline Control & $1 \%$ Tween 80 in water $(10 \mathrm{~mL} / \mathrm{kg})$ & $8.8 \pm 0.374$ & - \\
Diclofenac Na & 100 & $1.4 \pm 0.245^{*}$ & 83.833 \\
& 500 & $6.0 \pm 0.949$ & 31.611 \\
MLM & 1000 & $4.0 \pm 1.304^{*}$ & 54.389 \\
& 2000 & $3.2 \pm 0.917^{*}$ & 63 \\
\hline
\end{tabular}

Values are presented as mean $\pm \operatorname{SEM}(n=5)$. One way ANOVA followed by Dunnett's multiple comparisons was performed to analyze this dataset. ${ }^{*} P<0.05$ was considered statistically significant when compared against control.

TABLE 4: Effect of MLM extracts of $M$. repandus in xylene induced ear edema test.

\begin{tabular}{lccc}
\hline Group & Doses $(\mathrm{mg} / \mathrm{kg})$ & Ear weight difference $(\mathrm{mg})$ & Inhibition $(\%)$ \\
\hline Control & 1\% Tween 80 in water $(10 \mathrm{~mL} / \mathrm{kg})$ & $2.860 \pm 0.206$ & - \\
Diclofenac Na & 100 & $0.320 \pm 0.0663^{*}$ & 88.811 \\
& 500 & $2.840 \pm 0.548$ & 0.7 \\
MLM & 1000 & $0.860 \pm 0.420^{*}$ & 70 \\
& 2000 & $0.600 \pm 0.164^{*}$ & 79.02 \\
\hline
\end{tabular}

Values are presented as mean $\pm \operatorname{SEM}(n=5)$. One way ANOVA followed by Dunnet's multiple comparisons was performed to analyze this dataset. ${ }^{*} P<0.05$ was considered statistically significant when compared against control.

3.3. Tail Immersion Test. M. repandus showed significant increase in latency time after the first hour at a dose of $2000 \mathrm{mg} / \mathrm{kg}$ as shown in Table 2 . Pentazocine significantly increased $(P<0.05)$ latency time at each specific hour.

3.4. Acetic Acid Writhing Test. Table 3 showed the effect of the methanolic extract of $M$. repandus on acetic acid induced writhing in mice. At the dose of $1000 \mathrm{mg} / \mathrm{kg}$ and $2000 \mathrm{mg} / \mathrm{kg}$ body weight, the extract produced significant $54.39 \%$ and $63 \%$ writhing inhibition $(P<0.05)$ in test animals, respectively. The extract reduced number of writhing responses in a dose dependent manner. Diclofenac Na showed $83.83 \%$ inhibition of writhing.

3.5. Xylene Induced Ear Edema Test. Table 4 represents effects of MLM extracts with different doses in xylene induced ear edema model. Here MLM extract showed dose dependent $\%$ inhibition of ear edema. $2000 \mathrm{mg} / \mathrm{kg}$ dose of this extract presented highest significance in reduction in edema weight $(P<0.05)$ with maximum \% inhibition (79.02) in comparison with other doses. The extract reduced weight of edema in a dose dependent manner. Standard Diclofenac Na was found to present the highest inhibition $(88.81 \%)$ of ear edema.
3.6. Cotton Pellet Induced Granuloma Model. Table 5 presents the effects of different doses of methanol extract on cotton pellet granuloma test. MLM exhibited dose dependent inhibition of granular formation. $2000 \mathrm{mg} / \mathrm{kg}$ dose presented the highest granuloma formation inhibition (24.34\%) with significant value $P<0.05$. In this model the extract presented dose dependent inhibition of granuloma formation. Standard drug Diclofenac Na showed the highest 32.57\% inhibition.

\section{Discussion}

As preliminary phytochemical screening performed, it could be suggested that the antinociceptive and anti-inflammatory effects of leaf extract of $M$. repandus may be due to its content likealkaloids, carbohydrates, glycosides, flavonoids, saponins, and tannins. The effect of extract with its various doses like $500 \mathrm{mg} / \mathrm{kg}, 1000 \mathrm{mg} / \mathrm{kg}$, and $2000 \mathrm{mg} / \mathrm{kg}$ against acute inflammation was observed through using xylene induced ear edema in mice. This method is generally considered as one of the standard methods for detecting the effectiveness of anti-inflammatory agents [13]. Xylene initiates acute inflammatory response which leads to serious edematous changes and vasodilation of skin when topically applied 
TABLE 5: Effects of different doses of MLM extract of M. repandus in cotton pellet induced granuloma model.

\begin{tabular}{lccc}
\hline Group & Doses $(\mathrm{mg} / \mathrm{kg})$ & Granuloma wt. $(\mathrm{mg} / \mathrm{mg}$ cotton) & Inhibition $(\%)$ \\
\hline Control & $1 \%$ Tween 80 in water $(10 \mathrm{~mL} / \mathrm{kg})$ & $4.765 \pm 0.225$ & - \\
Diclofenac Na & 100 & $3.213 \pm 0.160^{*}$ & 32.57 \\
& 500 & $4.451 \pm 0.206$ & 6.6 \\
MLM & 1000 & $3.6474 \pm 0.166^{*}$ & 23.5 \\
& 2000 & $3.605 \pm 0.207^{*}$ & 24.34 \\
\hline
\end{tabular}

Values are presented as mean $\pm \operatorname{SEM}(n=5)$. One way ANOVA followed by Dunnet's multiple comparisons was performed to analyze this dataset. ${ }^{*} P<0.05$ was considered statistically significant when compared against control.

to the surfaces of the ear of mice [14-17]. According to present findings where significant results were obtained at $1000 \mathrm{mg} / \mathrm{kg}$ and $2000 \mathrm{mg} / \mathrm{kg}$ doses of extract (Table 4), it can be easily hypothesized that the leaf extract of $M$. repandus may exhibit anti-inflammatory activity through inhibiting xylene induced inflammatory response and thus ultimately decreases vasodilation and edematous condition of the ear skin of mice. Findings revealed that leaf extract of $M$. repandus showed moderate to strong effect against acute inflammation.

The abdominal contraction response induced by acetic acid is a very sensitive process which is used to screen the peripheral analgesic effect [18] and such abdominal contraction response is supposed to involve local peritoneal receptors [19]. In mice, acetic acid has been attributed to the release of arachidonic acid, which also results in the synthesis of prostaglandin through the enzyme called cyclooxygenase [20]. Acetic acid produced an abdominal writhing response due to peripheral nociceptive sensitization by prostaglandin. This method is also related to increased levels of prostanoids in general, for example, prostaglandin E2 (PGE2) and prostaglandin $\mathrm{F} 2 \alpha$ (PGF2 $\alpha$ ) as well as lipoxygenase products in peritoneal fluids [21-24]. Inflammation due to intraperitoneal injection of acetic acid also causes the release of endogenous substances like bradykinin, serotonin, and histamine, which stimulate the central nociceptive neurons $[25$, 26]. Any substance which causes the inhibition of the acetic acid induced writhing may have analgesic effect preferably through the inhibition of prostaglandin biosynthesis, which is actually known as a peripheral mechanism of pain inhibition. The significant analgesic effects were observed for methanolic extract of M. repandus at the doses of $1000 \mathrm{mg} / \mathrm{kg}$ and $2000 \mathrm{mg} / \mathrm{kg}$ which actually buttress the antinociceptive activity of this extract (Table 3). These results of the significant reduction in the number of acetic acid induced writhing responses strongly suggest that the extract retains peripheral analgesic activity through inhibition of local peritoneal receptors or arachidonic acid pathways, involving cyclooxygenases and/or lipoxygenases. Thus prostaglandin synthesis is remarkably decreased and at the same time approves traditional use of $M$. repandus for the relief of any inflammatory pain.

It has been reported that both stem and root extracts of $M$. repandus possessed a free radical scavenging activity, which could give a beneficial action against pathological alterations like edematous conditions [27]. They also found that stem and root extracts of $M$. repandus contained flavonoids (phenolic) and tannins (polyphenolic) like phytoconstituents. Both flavonoids and tannins possessed antioxidant activity because of their redox properties which let them act as reducing agents and quencher of singlet oxygen [28-31]. Our study also found tannins and flavonoids in leaf extract of M. repandus. Some studies have already claimed that flavonoids also possessed anti-inflammatory action [32-34]. Therefore, both anti-inflammatory and antioxidant effect could be supposed either as the protective action against any oxidative stress or inhibition of enzymes (e.g., cyclooxygenase) of prostaglandin pathway of inflammatory process.

The cotton pellet granuloma in mice is an excellent chronic inflammatory model that was selected to investigate chronic inflammation (the proliferative phase). Inflammatory response like extravasations, formation of granuloma, and various biochemical exudates due to cotton pellet can be readily detected through this technique [35]. Potent antiinflammatory response was observed with methanolic extract of M. repandus at doses of $1000 \mathrm{mg} / \mathrm{kg}$ and $2000 \mathrm{mg} / \mathrm{kg}$; thus, the extract produced a significant dose dependent inhibition of granuloma formation at the site of inflammation in animal model (Table 5), thereby suggestive of its activity in the transudative phase and proliferative phase of inflammation which ultimately leads to significant reduction in weight of cotton pellets in comparison with pellet control mice. Our earlier phytochemical study revealed the presence of flavonoids in methanolic extract of $M$. repandus. Some studies have already demonstrated the presence of various flavonoids like quercetin, hesperidin, luteolin responsible for significant antinociceptive, and/or anti-inflammatory activities [36-40]. Therefore, it could be easily assumed that the antinociceptive and anti-inflammatory effects of the methanolic extract of $M$. repandus may be due to the contents of flavonoids.

Thermal nociception model like tail immersion method was used to evaluate the central mechanism of analgesic activity which is known to elevate the pain threshold of mice towards heat [41]. It was found that the stem of $M$. repandus possesses the best anti-inflammatory activity [42]. But we found that the methanolic extract of $M$. repandus leafpossesses not only antinociceptive but also anti-inflammatory activity. This test is useful to identify the involvement of the opioid receptors in the action of any analgesic agents that give effect in the central mechanisms [43]. In this heat induced method, methanolic extract of $M$. repandus leaf particularly at $2000 \mathrm{mg} / \mathrm{kg}$ dose significantly prolonged the latency period $(P<0.05)$, which actually suggests the antinociceptive 
activity of the extract and which may significantly involve central mechanism of action through activation of the opioid receptor stimulation (Table 2 ). It was found that tannins had antinociceptive activity [44]. It was also showed that alkaloids also possessed the ability to inhibit pain perception [45]. Preliminary phytochemical studies confirmed the presence of both alkaloids and tannins. Further studies at molecular level also may provide lucid information of their sites and mechanism of actions.

The results and the above discussion are actually suggestive of the antinociceptive and anti-inflammatory actions for the methanolic extract of $M$. repandus. However, the mechanism of these actions still remains ambiguous, and the active chemical compounds responsible for both the antinociceptive and anti-inflammatory activities of the extract remained to be elucidated at molecular levels.

\section{Conclusion}

To finish off, it is not yet confirmed truly about how this leaf extract could have versatile therapeutic properties. There is every possibility of recommending that the bioactive compounds present in the methanolic leaf extract may be responsible for many sided effects. However, further detailed studies on the efficacy, potency, and safety profile would be essential to segregate the bioactive compounds and find out their underlying molecular mechanism of action which will guarantee their clinical worth.

\section{Conflict of Interests}

The authors declare that there is no conflict of interests regarding the publication of this paper.

\section{Acknowledgments}

The authors are thankful to Professor M.D. Shahabuddin K Choudhuri as well as the Pharmacology Laboratory, Department of Pharmacy, Jahangirnagar University, for providing a sufficient number of animals to complete in vivo experiments and wish to thank the Laboratory of Natural Products Research, Jahangirnagar University, for providing logistic support to complete in vitro experiment in this research work.

\section{References}

[1] C. Rivière, V. Nguyen Thi Hong, Q. Tran Hong et al., "Mallotus species from Vietnamese mountainous areas: phytochemistry and pharmacological activities," Phytochemistry Reviews, vol. 9, no. 2, pp. 217-253, 2010.

[2] M. van Chau, M. H. Le, and V. K. Phan, "Chemical investigations and biological studies of Mallotus apelta. VI. Cytotoxic constituents from Mallotus apelta," Tap Chi Hoa Hoc, vol. 43, pp. 5-6, 2005.

[3] P. van Kiem, C. van Minh, H. T. Huong, N. H. Nam, J. J. Lee, and Y. H. Kim, "Pentacyclic triterpenoids from Mallotus apelta," Archives of pharmacal research, vol. 27, no. 11, pp. 1109-1113, 2004.
[4] W. Chuakul, "Stemona hutanguriana sp. nov. (Stemonaceae) from Thailand," Kew Bulletin, vol. 55, no. 4, pp. 977-980, 2000.

[5] R. Saijo, G. I. Nonaka, and I. Nishioka, "Tannins and related compounds. LXXXVII. Isolation and characterization of four new hydrolyzable tannins from the leaves of Mallotus repandus," Chemical and Pharmaceutical Bulletin, vol. 37, no. 10, pp. 26242630, 1989.

[6] W. S. Kan, Manual of Vegetable Drugs in Taiwan. Part 2, Chinese Medicine Publishing, Taipei, Taiwan, 1973, (Chinese).

[7] C. C. Lin and W. S. Kan, "Medicinal plants used for the treatment of hepatitis in Taiwan," The American Journal of Chinese Medicine, vol. 18, pp. 35-43, 1990.

[8] S. De, Y. N. Dey, and A. K. Ghosh, "Phytochemical investigation and chromatographic evaluation of the different extracts of tuber of Amorphaphallus paeoniifolius (Araceae)," International Journal of Research in Pharmaceutical and Biomedical Sciences, vol. 1, no. 5, pp. 150-157, 2010.

[9] W. Toma, J. S. Gracioso, C. A. Hiruma-Lima, F. D. P. Andrade, W. Vilegas, and A. R. M. Souza Brito, "Evaluation of the analgesic and antiedematogenic activities of Quassia amara bark extract," Journal of Ethnopharmacology, vol. 85, no. 1, pp. 19-23, 2003.

[10] R. Koster, M. Anderson, and E. J. De-Beer, "Acetic acid analgesic screening," Federation Proceedings, vol. 18, pp. 412-417, 1959.

[11] Y. Dai, L. H. Liu, and J. P. Kou, "Anti-inflammatory effect of aqueous extract of Wu-HU-Tang," China Pharmaceutical University, vol. 6, pp. 362-364, 1995.

[12] K. F. Swingle and F. E. Shideman, "Phases of the inflammatory response to subcutaneous implantation of a cotton pellet and their modification by certain anti-inflammatory agents," Journal of Pharmacology and Experimental Therapeutics, vol. 183, no. 1, pp. 226-234, 1972.

[13] H. Hosseinzadeh, M. Ramezani, and N. Namjo, "Muscle relaxant activity of Elaeagnus angustifolia L. fruit seeds in mice," Journal of Ethnopharmacology, vol. 84, no. 2-3, pp. 275-278, 2003.

[14] K.-H. Cho, H.-D. Kim, B.-W. Lee, M.-K. Lim, and S. K. Ku, "Effects of magnetic infrared laser on xylene-induced acute inflammation in mice," Journal of Physical Therapy Science, vol. 20, no. 4, pp. 255-259, 2008.

[15] H.-D. Kim, H.-R. Cho, S.-B. Moon et al., "Effects of $\beta$-glucan from Aureobasidium pullulans on acute inflammation in mice," Archives of Pharmacal Research, vol. 30, no. 3, pp. 323-328, 2007.

[16] R. De La Puerta, E. Martinez, L. Bravo, and M. C. Ahumada, "Effect of silymarin on different acute inflammation models and on leukocyte migration," Journal of Pharmacy and Pharmacology, vol. 48, no. 9, pp. 968-970, 1996.

[17] A. Sowemimo, F. Samuel, and M. S. Fageyinbo, "Anti-inflammatory activity of Markhamia tomentosa (Benth.) K. Schum. Ex Engl. ethanolic leaf extract," Journal of Ethnopharmacology, vol. 149, no. 1, pp. 191-194, 2013.

[18] O. O. Adeyemi, A. A. Adeneye, and T. E. Alabi, "Analgesic activity of the aqueous seed extract of Hunteria umbellata (K. Schum.) hallier F. in rodents," Indian Journal of Experimental Biology, vol. 49, no. 9, pp. 698-703, 2011.

[19] G. A. Bentley, S. H. Newton, and J. Starr, "Studies on the antinociceptive action of $\alpha$-agonist drugs and their interactions with opioid mechanisms," British Journal of Pharmacology, vol. 79, no. 1, pp. 125-134, 1983. 
[20] P. Davies, P. J. Bailey, M. M. Goldenberg, and A. W. FordHutchinson, "The role of arachidonic acid oxygenation products in pain and inflammation.," Annual review of immunology, vol. 2, pp. 335-357, 1984.

[21] J. D. Levine, W. Lau, G. Kwiat, and E. J. Goetzl, "Leukotriene B4 produces hyperalgesia that is dependent on polymorphonuclear leukocytes," Science, vol. 225, no. 4663, pp. 743-745, 1984.

[22] A. K. Dhara, V. Suba, T. Sen, S. Pal, and A. K. N. Chaudhuri, "Preliminary studies on the anti-inflammatory and analgesic activity of the methanolic fraction of the root extract of Tragia involucrata Linn," Journal of Ethnopharmacology, vol. 72, no. 1-2, pp. 265-268, 2000.

[23] N. D. Yadu, D. Shankhajit, and K. G. Ajoy, "Evaluation of Analgesic activity of methanolic extract of Amorphophalus paeonifolius tuber by tail flick and acetic acid-induced writhing response method," International Journal of Pharma and Bio Sciences, vol. 1, pp. 662-668, 2010.

[24] R. S. Ghule, R. Venkatanarayan, S. P. Thakare, H. Jain, and P. R. Ghule, "Analgesic activity of Cuscuta campestris Yuncker a parasitic plant grown on Nerium indicum Mill," Journal of Advanced Pharmaceutical Technology \& Research, vol. 1, pp. 4551, 2011.

[25] P. R. Verma, A. A. Joharapurkar, V. A. Chatpalliwar, and A. J. Asnani, "Antinociceptive activity of alcoholic extract of Hemidesmus indicus R.Br. in mice," Journal of Ethnopharmacology, vol. 102, no. 2, pp. 298-301, 2005.

[26] A. Rathi, C. V. Rao, S. Khatoon, and S. Mehrotra, "Ethnopharmacological evaluation of Peristrophe bicalyculata Nees for antiinflammatory and analgesic activity," Natural Product Sciences, vol. 9, no. 3, pp. 195-199, 2003.

[27] J.-M. Lin, C.-C. Lin, M.-F. Chen, T. Ujiie, and A. Takada, "Scavenging effects of Mallotus repandus on active oxygen species," Journal of Ethnopharmacology, vol. 46, no. 3, pp. 175-181, 1995.

[28] Y. Kimura, H. Okuda, T. Okuda, T. Hatano, I. Agata, and S. Arichi, "Effects of extracts of leaves of Artemisia species and caffeic acid and chlorogenic acid on lipid metabolic injury in rats fed peroxidized oil," Chemical and Pharmaceutical Bulletin, vol. 33, no. 5, pp. 2028-2034, 1985.

[29] T. Hatano, R. Edamatsu, M. Hiramatsu et al., "Effects of the interaction of tannins with co-existing substances. VI. Effects of tannins and related polyphenols on superoxide anion radical, and on DPPH radical," Chemical and Pharmaceutical Bulletin, vol. 37, pp. 2016-2021, 1989.

[30] T. Okuda, Y. Kimura, T. Yoshida, T. Hatano, H. Okuda, and S. Arichi, "Studies on the activities of tannins and related compounds from medicinal plants and drugs. I. Inhibitory effects on lipid peroxidation in mitochondria and microsomes of liver," Chemical and Pharmaceutical Bulletin, vol. 31, no. 5, pp. 1625-1631, 1983.

[31] T. Yoshida, K. Mori, T. Hatano et al., "Studies on inhibition mechanism of auto-oxidation by tannins and flavonoids. V. Radical scavenging effects of tannins and related polyphenols on DPPH," Chemical and Pharmaceutical Bulletin, vol. 37, pp. 1919-1921, 1989.

[32] M. E. Gerritsen, W. W. Carley, G. E. Ranges et al., "Flavonoids inhibit cytokine-induced endothelial cell adhesion protein gene expression," American Journal of Pathology, vol. 147, no. 2, pp. 278-292, 1995.

[33] E. Middleton Jr., "Effect of plant flavonoids on immune and inflammatory cell function," Advances in Experimental Medicine and Biology, vol. 439, pp. 175-182, 1998.
[34] G. Di Carlo, N. Mascolo, A. A. Izzo, and F. Capasso, "Flavonoids: old and new aspects of a class of natural therapeutic drugs," Life Sciences, vol. 65, no. 4, pp. 337-353, 1999.

[35] S. Singh, A. Tomar, and H. S. Chandel, "Anti-inflammatory effect of hydroalcoholic extract of fruit of Ficus carica," International Journal of Drug Research and Technology, vol. 2, no. 6, pp. 440-445, 2012.

[36] E. Küpeli and E. Yesilada, "Flavonoids with anti-inflammatory and antinociceptive activity from Cistus laurifolius L. leaves through bioassay-guided procedures," Journal of Ethnopharmacology, vol. 112, no. 3, pp. 524-530, 2007.

[37] S. R. Mada, M. R. Metukuri, L. Burugula, P. Reddanna, and D. R. Krishna, "Antiinflammatory and antinociceptive activities of gossypin and procumbentin-cyclooxygenase-2 (COX-2) inhibition studies," Phytotherapy Research, vol. 23, no. 6, pp. 878-884, 2009.

[38] U. R. Ghogare, S. A. Nirmal, R. Y. Patil, and M. D. Kharya, "Antinociceptive activity of Gynandropsis gynandra leaves," Natural Product Research, vol. 23, no. 4, pp. 327-333, 2009.

[39] N. Erdemoglu, E. K. Akkol, E. Yesilada, and I. Caliş, "Bioassayguided isolation of anti-inflammatory and antinociceptive principles from a folk remedy, Rhododendron ponticum L. leaves," Journal of Ethnopharmacology, vol. 119, no. 1, pp. 172-178, 2008.

[40] M. K. Saeed, Y. Deng, R. Dai, W. Li, Y. Yu, and Z. Iqbal, "Appraisal of antinociceptive and anti-inflammatory potential of extract and fractions from the leaves of Torreya grandis Fort Ex. Lindl," Journal of Ethnopharmacology, vol.127, no. 2, pp. 414418, 2010.

[41] C. A. Hiruma-Lima, J. S. Gracioso, E. J. B. Bighetti, L. Germonsén Robineou, and A. R. M. Souza Brito, "The juice of fresh leaves of Boerhaavia diffusa L. (Nyctaginaceae) markedly reduces pain in mice," Journal of Ethnopharmacology, vol. 71, no. 1-2, pp. 267-274, 2000.

[42] C. C. Lin, J. M. Lin, and H. F. Chiu, "Studies on folk medicine "thang-kau-tin" from Taiwan. (I). The anti-inflammatory and liver-protective effect," American Journal of Chinese Medicine, vol. 20, no. 1, pp. 37-50, 1992.

[43] M. Moniruzzaman and M. Z. Imam, "Evaluation of antinociceptive effect of methanolic extract of leaves of Crataeva nurvala Buch.-Ham," BMC Complementary and Alternative Medicine, vol. 14, article 354, 2014.

[44] V. R. Ramprasath, P. Shanthi, and P. Sachdanandam, "Immunomodulatory and anti-inflammatory effects of Semecarpus anacardium Linn. nut milk extract in experimental inflammatory conditions," Biological and Pharmaceutical Bulletin, vol. 29, no. 4, pp. 693-700, 2006.

[45] F. I. Uche and J. S. Aprioku, "The phytochemical constituents, analgesic and anti-inflammatory effects of methanol extract of Jatropha curcas leaves in mice and Wister albino rats," Journal of Applied Sciences and Environmental Management, vol. 12, no. 4, pp. 99-102, 2008. 

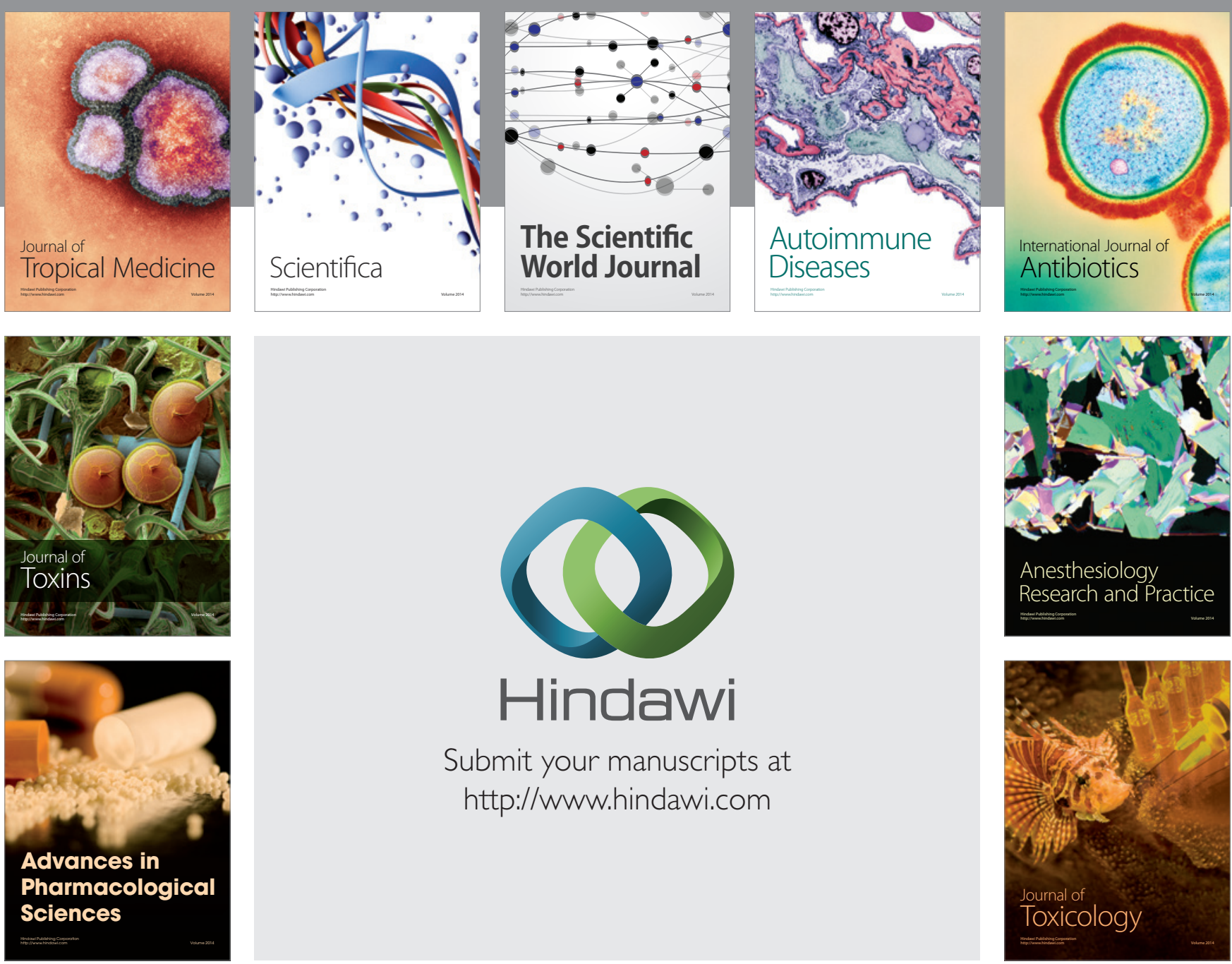

\section{Hindawi}

Submit your manuscripts at

http://www.hindawi.com
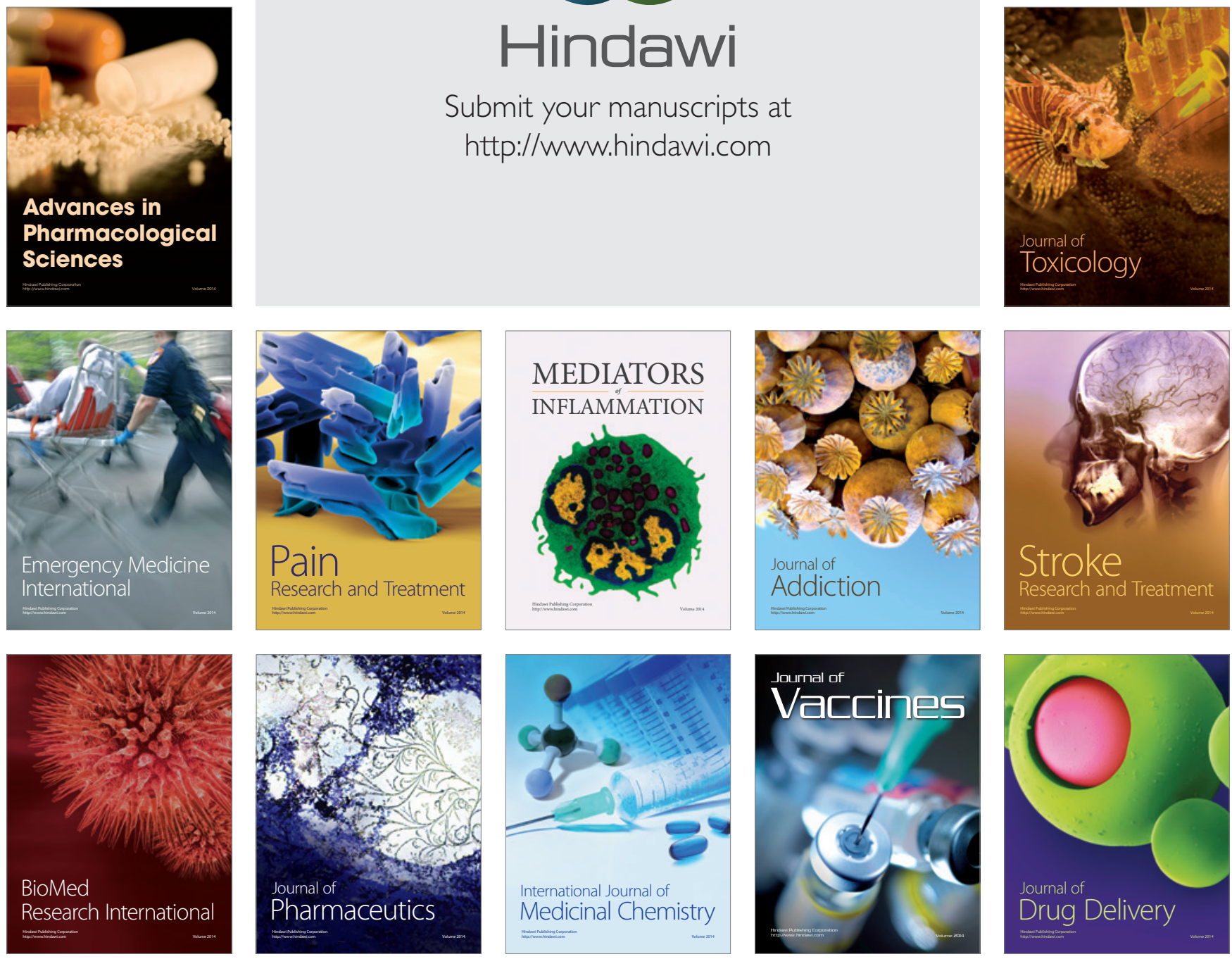